\title{
Universidade e prioridade sociais
}

\author{
JACQUES MARCOVITCH
}

$\mathrm{C}$

OMIDA, EMPREGO E EDUCAÇÃO - o professor Darcy Ribeiro respondia sempre, de forma contundente, quando perguntado sobre os grandes problemas do Brasil. Ele estava certo nesta síntese bruta, mas há, por trás dela, uma teia imensa de fatores que reclamam não apenas o trabalho de governos circunstanciais. Esse desafio, incessante por sua natureza, é de toda a sociedade. E, por maiores êxitos pontuais que se obtenha, restará muito por fazer. Na melhor das hipóteses, para aperfeiçoar as soluções encontradas.

Se quisermos firmar um conceito para reflexão mais abrangente, poderemos dizer que o dilema do Brasil de hoje, para não dizer do mundo inteiro, é harmonizar a competitividade e a justiça social. Exigências da globalização no que se refere às inovações tecnológicas chegaram a tal ponto que não há reversão possível, em que pesem seus efeitos na redução da mão-de-obra, principalmente a industrial. Enquanto se redimensiona o perfil do mercado de trabalho, buscando a expansão cada vez maior do setor de serviços, milhões de famílias ficarão sem qualquer renda - o que é assustador. Cresce, diante disso, a urgência na implementação de políticas que amparem indivíduos carentes em sentido vertical: desempregados, doentes, ignorantes e vítimas preferenciais da violência ou do desenvolvimento não-sustentável.

A evolução demográfica brasileira nos últimos cem anos foi a mais acentuada em comparação com os demais países do continente americano e do mundo (1). O século se iniciou com uma população de 17 milhões de habitantes. Em 1925 já éramos 30, em 1950, 53, e em 1975, 108 milhões. Entraremos no século XXI com uma população de aproximadamente 170 milhões de habitantes, resultante da taxa de natalidade ainda elevada, mas em declínio, além da visível redução na taxa de mortalidade e uma política migratória sempre generosa. O Brasil é o único país no mundo que testemunhou tão expressiva evolução populacional nos últimos cem anos. Isso exige um rápido aperfeiçoamento da infra-estrutura social.

Tendo os olhos postos neste quadro, a Universidade de São Paulo vem mobilizando a comunidade interna para refletir e propor soluções (2). 
Consideremos inicialmente a questão da saúde, pois o envolvimento de uma universidade com tal questão tem na pesquisa o seu referencial de mais forte significância (3).

\section{Saúde}

O progresso das ciências da saúde responde, em todos os países, pelo aumento da expectativa de vida. Segundo a OMS, as taxas de mortalidade, mesmo nos países em desenvolvimento, vêm declinando significativamente. Nesses países a expectativa média de vida, que era de 62 anos em 1990, alcançará em 2020 a faixa de quase 70 anos. Também para 2020 prevê-se que o Brasil estará entre os 10 países com maior proporção de idosos. Mas há uma questão ética implícita no delicado contexto da saúde pública. Não podemos analisá-la somente com dados e projeções estatísticas. Enquanto uns chegam a uma velhice saudável, outros ainda morrem de fome ou de doenças facilmente controláveis. Nos Estados Unidos, por exemplo, o país mais rico do mundo, aproximadamente 40 milhões de pessoas ainda não têm assistência médica. Estabelece-se uma situação moralmente inaceitável.

A universidade lida com a questão saúde em termos diferenciados. Não há como encará-la usando apenas aspectos parciais das estatísticas. A universidade é crítica. A universidade tem a obrigação de ver a outra face das aparências. É neste avesso que se escondem, no plano da saúde, as nossas infelicidades.

A necessidade imperiosa de novas políticas públicas em nosso país não cessará enquanto houver brasileiros sem teto, sem comida, sem emprego e principalmente sem saúde, porque esta é a carência que, no mais das vezes, está associada a todas as outras.

$\mathrm{Na}$ questão saúde a universidade não pode ser apenas parceira dos governos, mas de todos os grupos sociais envolvidos com o tema. Neste sentido, cabe sublinhar uma das teses desenvolvidas pelo professor José Carvalheiro em sua contribuição para outro importante Dossiê publicado na revista Estudos Avançados. Para caracterizar a instância ideal de concepção e implementação de políticas públicas voltadas para a saúde, ele foi buscar acertadamente, no âmbito da sociologia política, o conceito de comunidade epistêmica. A comunidade epistêmica, diz o autor, não é composta apenas de cientistas. É uma espécie de coletivo do pensamento, em que se alinham políticos, governantes, empresários e todos aqueles que compartilham valores a respeito de um determinado tema de interesse público (4). 


\section{Ambiente}

Este conceito epistêmico aplica-se também à defesa do meio ambiente, envolvendo a comunidade que pensa e a comunidade que age. É necessária uma articulação contínua entre ambas. No Brasil, a militância ambientalista surgiu em meados da década de 70. Algumas entidades ligaram-se de imediato à comunidade científica e enfrentaram fortíssimos obstáculos criados pelo regime político então vigente. Basta recordar a estranha posição brasileira na Conferência de Estocolmo, em 1972, quando o general Costa Cavalcanti, representante do nosso governo, declarou textualmente, para assombro do mundo civilizado: "Um país que não alcançou o nível satisfatório mínimo para prover o essencial não está em condições de desviar recursos consideráveis para a proteção do meio ambiente".

Aqueles eram os tempos do chamado Brasil potência e de sucessivos projetos de impacto, freqüentemente hostis à natureza. Em paralelo aos desmatamentos e megaestradas abertas para fins propagandísticos, reforçavase o Estado repressivo, que limitava a cidadania até sua quase total anulação.

A insólita declaração em Estocolmo é algo inconcebível no regime democrático em que vivemos. Mas devemos relembrá-la para ilustrar mais ainda como foi desbravador o papel da militância ambientalista naqueles tempos. É importante que hoje, na universidade, locus de atuação dos cientistas, lembremos com reverência o esforço dos pioneiros neste bom combate. Sabemos que muitas vezes os excessos da ação militante deformam as boas causas, mas é imperioso, neste caso, considerar que foram úteis para a consolidação da causa ambiental no Brasil.

A Universidade de São Paulo sempre ocupou a vanguarda desta luta que hoje se tornou estratégica e essencial na plataforma dos grandes interesses nacionais. São inúmeros os estudos, teses, publicações e seminários promovidos pelos vários grupos de pesquisa voltados para a questão do desenvolvimento sustentável.

Ao contrário da modernização, que deseja o progresso a qualquer custo, a modernidade concilia o avanço econômico e o interesse social. A resultante primeira da modernização é o acúmulo de vantagens para grupos minoritários. A modernidade, pelo contrário, atualiza o país e reparte entre todos os benefícios desse aperfeiçoamento. O Brasil, como observou Raymundo Faoro, nem sempre tem buscado a modernidade e freqüentemente padece os efeitos da modernização (5). Neste processo de surtos, que se desfazem quando atingidos por outros da mesma origem, não há ganhos sociais, mas o reforço dos privilégios e da concentração de renda. Devemos 
buscar a modernidade e não a sua versão pervertida, que é a modernização. E o caminho para chegar a este objetivo passa pelo avanço da consciência ecológica em todos os níveis. Consciência dos governantes, consciência dos cidadãos em geral, consciência dos empreendedores.

\section{Segurança}

Já a formação de uma consciência coletiva em torno do fenômeno da violência é objetivo mais ambicioso e mais complexo. A percepção deste fenômeno não é homogênea nos vários segmentos da sociedade. Ter uma visão ponderada do conjunto de reações constitui um dever da academia. A violência não é - como alguns equivocadamente supõem - apenas um caso de polícia. É matéria de aspectos múltiplos, que também pode ser tratada na universidade e não somente nos órgãos de segurança. Tratado na universidade, não para que ela elabore planos de ação capazes de eliminar magicamente a criminalidade, mas para que forneça aos governos uma interpretação abrangente do problema e ajude a resolvê-lo. Isso deve ficar claro, porque freqüentemente surgem demandas com este viés distorcido e imediatista. Pede-se à universidade que tenha planos para tudo. Planos para a saúde pública, política industrial, desenvolvimento tecnológico, meio ambiente, desemprego, segurança. Esta é uma expectativa equivocada. O que a universidade pode e deve fornecer são elementos para o equacionamento de políticas públicas e não os formatos acabados e definitivos destas políticas.

Quando a USP foi chamada a contribuir para a elaboração de um programa emergencial de segurança pública, o nosso Núcleo de Estudos da Violência atendeu à demanda e produziu vários estudos com recomendações de grande alcance. Tais iniciativas demonstram que a Universidade vai muito além dos estudos teóricos. Mas evidentemente não lhe cabe o papel de conceber planos operacionais e detalhados em torno da questão da violência. Imaginar a Universidade como uma usina de proposições é não compreender a sua missão formadora de mentalidades e renovadora de conceitos.

O combate à violência é outra causa que mobiliza a sociedade em todo o mundo (6). Inegavelmente a criminalidade chegou em níveis insuportáveis em São Paulo, incluindo mortes, assaltos, seqüestros, estupros e um cortejo de crimes hediondos. Diante deste quadro há setores, com a melhor das intenções, que acabam cumprindo sua parte de forma distorcida. É o caso de certas campanhas contra a violência. Em algumas delas, o tom raivoso chega a lembrar a retórica dos políticos extremistas. Em outras, o combate à violência é usado como instrumento de marketing institucional para valorizar a imagem de determinadas emissoras. Chegou-se a usar, numa 
dessas campanhas, o testemunhal de um comunicador popular que faz da violência entre casais um grotesco artifício para ampliar a audiência do seu programa de TV. Há grandes riscos nestas iniciativas bem-intencionadas e nada instrutivas (7). O ideal seria uma campanha que tivesse o combate à violência como único interesse e por isso mesmo divulgada simultaneamente em todos os veículos - com mensagens verdadeiramente educativas e que não servissem a objetivos ideológicos ou de comercialização.

Mas não é apenas a mídia que erra na abordagem do tema. Os comunicadores não estão sozinhos em seus equívocos. Também os acadêmicos cometem deslizes inaceitáveis. Devo citar aqui uma desastrosa entrevista à imprensa brasileira de Steven Levitt, professor de Economia da Universidade de Chicago e que estranhamente foi citado como especialista em estudos sobre a violência.

O professor Levitt dita regras que supõe definitivas para eliminar a violência no Brasil, depois de passar apenas uma semana em nosso país. Convidado a fazer uma análise comparativa entre o Brasil e a Colômbia, no que diz respeito ao uso de drogas, disse textualmente que “...a Colômbia é exportadora de drogas e o Brasil é traficante”(8). Esta simplificação é tão despropositada como dizer que os Estados Unidos são um país de assassinos de presidentes porque lá aconteceram as mortes violentas de Abraham Lincoln e John Kennedy. Mas o professor Steven Levitt não julgou o seu despautério suficiente e afirmou, respondendo a uma pergunta, que se tivesse US\$ 100 mil para investir numa comunidade, não investiria na educação dos jovens, mas no aparato policial. Mesmo assim, pedindo mais polícia nas ruas, admite contraditoriamente: “... já estive na favela do Jacarezinho e não tive problemas. $\mathrm{O}$ único momento em que tive medo foi quando dois policiais me abordaram ...". A entrevista foi um acinte à correta reflexão acadêmica enfocando esta matéria delicada e complexa, que é a violência urbana. Matéria que não se pode tratar, como fez o jovem visitante, aplicando-se mecanicamente a fria lógica da teoria econômica.

Outro professor, curiosamente da mesma Universidade de Chicago, escandalizou a comunidade acadêmica em seu país aliando-se aos defensores do uso indiscriminado de armas de fogo. Indiferente aos recentes e terríveis episódios em que adolescentes assassinaram a tiros vários colegas numa escola norte-americana, o professor John R. Lott Jr. publicou o livro Mais armas, menos crimes (9). Nele, manejando habilmente relações estatísticas e dissecando o comportamento social como se examinasse apenas um demonstrativo econômico financeiro, o professor opõe-se aos justos esforços do presidente Clinton, que vem pedindo ao Congresso regras mais rígidas 
para limitar o acesso às armas. Até compreendemos quais setores da população, atingidos em sua segurança pelas ações impunes e cada vez mais ousadas do banditismo, recorram a este meio perigoso para defender-se, não se pode aceitar que essa tese desesperada prospere na Academia, onde a razão e o equilíbrio devem prevalecer.

Nos Estados Unidos a cultura do uso de armas é tradicional: cerca de 86 milhões de pessoas possuem até 240 milhões de armas de fogo. Se naquele país o governo esforça-se para inibir este hábito perigoso, mais razão ainda têm as nossas autoridades para caminhar na mesma direção, apesar de a forte resistência que estão enfrentando. Chegou o momento certo para que a universidade brasileira entre no debate e ilumine as consciências com as melhores ponderações.

A idéia de prender, punir e disseminar o uso de armas naturalmente deságua na tese de que os índices de pobreza não guardam relação direta com a violência. O desafio da universidade é demonstrar o peso desta relação e a importância de políticas preventivas, embora isso não implique o abandono da repressão policial que garanta a segurança da comunidade. Uma comunidade, registre-se, que em parte vem recusando políticas públicas identificadas com a proteção dos direitos humanos.

É dever de uma instituição plural, como a universidade, mostrar à sociedade que o regime democrático, em nenhuma hipótese, minimiza uma severa repressão ao crime. A idéia de que somente os regimes de força inibem o banditismo não tem sustentação histórica. Aqui mesmo, no Brasil, em períodos totalitários, não houve decréscimo da criminalidade.

A verdadeira democracia não tolera a violência - seja ela praticada pelo Estado ou por indivíduos fora da lei. A democracia deve garantir a paz pública, o respeito ao patrimônio, a segurança das famílias. Famílias de todas as classes, incluídas aquelas que não dispõem de segurança particular e não têm qualquer outro patrimônio além de suas vidas desamparadas.

\section{Trabalho}

Não há desamparo maior do que a falta de trabalho. A universidade precisa amadurecer e expor com bastante clareza uma visão do problema, porque ele reflete a mais importante questão social do nosso tempo. O trabalho é o fio que costura toda a história humana. O desemprego, hoje afligindo milhões de brasileiros, é a maior de todas as desconsiderações do Estado para com os seus cidadãos. O desemprego também leva o indivíduo à sua mais dolorosa crise, que é a autodesconsideração (10). 
Sabemos todos que uma revolução irreversível está acontecendo no mundo do trabalho: mudou radicalmente o conceito de mão-de-obra em todos os países. Evidentemente, há especificidades nesta mudança para as nações pobres e ricas, homens e mulheres, regiões diversas em cada país. Mas o fato é que, hoje, a empregabilidade precede o emprego na pauta das preocupações. Entre a vaga, cada vez mais rara, e o trabalhador que deseja ocupá-la, interpõe-se um volume de exigências jamais registrado. Tais exigências não mais se restringem ao domínio prático do ofício a ser exercido, mas envolvem a capacidade intelectual do trabalhador para adaptar-se às inovações tecnológicas. Inovações que podem surgir até no dia seguinte à sua contratação. Não basta mais ao assalariado desempenhar mecanicamente suas tarefas, mas exercer também uma função alimentadora. Ele não deve apenas cumprir ordens, deve igualmente propor idéias e soluções.

Esta nova realidade implica uma redefinição geral de atitudes em vários setores, principalmente na área educativa, nas empresas e nos sindicatos (11). Não há como ignorar os fatos. Novos cenários da economia sugerem que o emprego, em sua concepção atual, tende a desaparecer, substituído cada vez mais pelo trabalho autônomo. A sociedade, porém, em qualquer hipótese, terá a obrigação de oferecer meios que assegurem aos indivíduos não apenas a sobrevivência, mas um pleno bem estar-material e espiritual.

A universidade tem importante papel a desempenhar nesse contexto. Sendo ela vocacionalmente crítica, é fundamental que se debruce com apuro sobre o novo e delicado universo de análise do trabalho. Mesmo as teses que modernizam as relações trabalhistas devem sofrer depuração aguda e permanente. Será útil, por exemplo, impor limites à flexibilidade nos contratos de trabalho. Este cuidado vem sendo reclamado até mesmo pelas empresas, que enxergam nos contratos excessivamente flexíveis e de curta duração um estímulo à baixa lealdade dos empregados (12).

Não há item de relevância maior na agenda nacional. É importante que a universidade, buscando políticas adequadas para o seu encaminhamento, também o enquadre na dimensão da solidariedade, um dos mais caros valores acadêmicos. Não se trata apenas de compaixão pelos despossuídos, mas de empreender um exercício proativo. Se os novos tempos definem a capacitação como a única via de acesso ao trabalho - o que fazer com os idosos que não tiveram tempo de reciclar-se? O que fazer com os jovens que não dispõem de meios econômicos para responder às exigências do mercado? Como eliminar de vez o trabalho infantil? Como retificar o modelo econômico em nosso país, direcionando-o para um apoio maior à produção e para o alargamento das oportunidades profissionais? 


\section{Educação}

Se tantas indagações ficam sem resposta quando tratamos do emprego, outras muitas também persistem quando falamos da educação no Brasil. Não apenas a educação que oferecemos em nossos bancos acadêmicos. Não apenas a educação formal, em todos os seus níveis, mas também aquela voltada para o exercício da cidadania e que se adquire por meios amplos e difusos: na escola, no convívio social, na família, no trabalho. A educação, para a universidade contemporânea, deixou de ser apenas uma rotina interna. Tornou-se um alvo permanente a ser contemplado no espectro nacional de políticas públicas - e para receber continuamente os frutos dos nossos estudos específicos e da nossa reflexão.

Aqui chegamos a outra prioridade social. A educação é o único valor que tem presença simultânea entre os direitos e os deveres de cada indivíduo. Todos os homens merecem o benefício da instrução e, uma vez instruídos, devem obediência às regras fulcrais da cidadania: a solidariedade, o respeito pelo outro, a obrigação de ser útil (13).

Fixado este princípio de ordem geral, contemplemos a Educação em sua realidade concreta no Brasil de hoje. Neste cenário, a questão do ensino tem uma face dupla. De um lado, centra-se em variáveis materiais, abrangendo recursos disponíveis / salários dos professores / equipamentos escolares/ distribuição de renda; de outro lado, em matrizes teóricas, nas quais se debate, sem acordo previsível, o mais adequado modelo pedagógico.

Há consenso com relação à precariedade de verbas, embora o governo federal empreenda esforços recentes para atenuar o quadro no que diz respeito ao ensino fundamental. Mas a ação do Ministério da Educação, nesse nível, é apenas normativa. Cabe aos estados e municípios, com latitude bastante ampla, todas as responsabilidades de ordem prática. Cobrar exclusivamente do MEC uma solução eficaz é apostar demasiado em regras burocráticas e subestimar a questão da racionalidade nos gastos. Nessa perspectiva, o Fundef, gerido conjuntamente pelos governos estaduais e prefeituras, com eventual socorro da União, é um caminho que naturalmente reclama aperfeiçoamentos. Merece discussões, mas não pode ser desprezado. A questão do ensino fundamental, entretanto, não pode ser reduzida ao simples confronto municipalização versus estadualização. $\mathrm{Na}$ base de tudo está o grave problema social da má distribuição de renda. Enquanto persistirem os desníveis sociais e o quadro de miséria que afetam amplas camadas populares, o acesso à escola, mesmo gratuita, ficará prejudicado. 
No que diz respeito ao ensino superior, cumpre unicamente ao MEC fechar a equação das universidades federais, ainda objeto de clara discordância. A autonomia das instituições, fundada no repasse de recursos que garantam sua manutenção, deve estar agregada a fatores de desempenho. Tais fatores norteariam a liberação de verbas diferenciais. Eis, em resumo, a posição das maiores universidades de pesquisa no país. O problema não se esgota em mero encontro de contas, porém este ponto, mais do que qualquer outro, deve atrair as atenções dos interessados (14).

A ampliação do acesso ao ensino médio e melhoria do seu desempenho são desafios aos governos estaduais, mas a União tomou a recente iniciativa de implantar o Enem - ainda questionado, mas que pode resultar pelo menos no mapeamento das deficiências. Para usar números freqüentemente invocados pelo professor José Goldemberg, o ensino privado de segundo grau abrange apenas $30 \%$ das matrículas, enquanto o poder público responde por $70 \%$ delas. Neste último percentual a participação municipal é baixa (4\%) e a federal mais ainda (3\%). Não se veja um bom desempenho neste indicador de 70\%. Em nosso país, na faixa etária dos 15 aos 19 anos, o número de alunos matriculados no ensino médio é de apenas 17\% contra 55\% do México, se quisermos estabelecer comparação na América Latina. Entre os países totalmente desenvolvidos, a taxa mais alta de matrículas, nessa mesma faixa etária, cabe ao Japão, com 96\%. Esta nossa deficiência tem suas raízes no baixíssimo número de alunos pobres que chega a concluir o primeiro grau (15). Novamente estamos diante do problema básico, a má distribuição de renda.

Todas as prioridades brasileiras em discussão na academia têm como causa ou efeito a questão social, resumida por Darcy Ribeiro no trinômio comida-educação-emprego. Por isso a universidade vem chamando insistentemente a atenção do governo para dar a essa questão o mesmo peso que atribuiu à política de estabilização monetária. É inegável a importância do ajuste nas contas públicas e do controle permanente da inflação. A estabilidade monetária tornou ainda mais clara a distância sócio-econômica existente entre os segmentos que compõem a nossa sociedade. Em cinco anos a sociedade já pagou uma conta muito elevada por esta fragmentação crescente e ameaçadora. É hora da contrapartida, sob pena de comprometermos a coesão social - um fator decisivo para a governabilidade que todos desejamos.

\section{Notas}

1 Jacques Dupânquier. La population mondiale an $X X^{e}$ siècle. Paris, Presses Universitaires de France, 1999. 
2 Um exemplo recente foi a realização da série de jornadas "A USP fala sobre ...”, que teve como temas a saúde, a violência, o emprego e relações do trabalho, a educação e o meio ambiente.

3 A jornada "USP fala sobre saúde" produziu cerca de 50 contribuições escritas, abrangendo os mais diversos campos de investigação nesta área. Os textos, juntamente com as palestras e intervenções, já foram publicados em dossiê desta revista.

4 José R. Carvalheiro. Os desafios para a saúde. Estudos Avançados, v. 13, n. 35, jan./abr. 1999.

5 Raymundo Faoro. A questão nacional: a modernização. Estudos Avançados, n. 14, jan./abr. 1992.

6 Delbert S. Elliott; Beatrix A. Hamburg \& Kirk R. Williams. Violence in American schools. Cambridge, Cambridge University Press, 1998.

7 Ignacio Ramonet. La tyrannie de la communication, Paris, Éditions Galilée, 1999.

8 Época, edição 62, 26 jul. 1999.

9 John R. Lott Jr. Mais armas, menos crimes, Makron Books, 1999.

10 Centro de Psicologia Aplicada ao Trabalho. Cadernos de Psicologia Social do Trabalho, Instituto de Psicologia, Universidade de São Paulo, v. 1, n. 1, 1998.

11 International Labour Office. Employing youth: promoting employment-intensive growth. Geneve. 1999.

12 Frederick F. Reichheld \& Thomas Teal - The loyalty effect. The hidden force behind growth, profits, and lasting value. Boston, HBSP, 1996.

13 Edgar Morin. La tête bien faite - Repenser la réforme - Repenser la pensée. França, Éditions du Seuil, 1999.

14 Instituto de Estudos Avançados. A presença da universidade pública - Universidade de São Paulo, 2000.

15 José Goldemberg. O repensar da educação no Brasil. Estudos Avançados, v. 7, n. 18, maio/ago. 1993.

Jacques Marcovitch é professor da Faculdade de Economia, Administração e Contabilidade (FEA) e reitor da Universidade de São Paulo (USP). 